ing line: 'Am I going to die, nurse?' It is developed well in early chapters but, curiously, the nursing aspects then tend to fade away.

Faced with such a book, it is always tempting for a reviewer to ponder the choice and balance of topics: why some are included and others left out. Also, when attempts are made to build bridges between academic disciplines and the social realities of nursing (a graveyard for many aspiring authors) balance and relevance are all-important if the reader's attention is to be held. Overall, this reviewer appreciated the choice of topics but found it curious that pressing and timely issues such as contraception, population explosion, mental health, and substance abuse are not considered, whereas abortion and reproductive technology receive extensive coverage: perhaps the latter are viewed as more directly healthrelated but many nurses might question this assumption.

The first two chapters, on moral thinking and moral deliberation introduce basic ideas. Chapters three to eight are highly relevant to nurses, with many important aspects of practice discussed. However, the book is patchy in its coverage: chapters eight to twelve covering abortion, reproductive technology, death and dying, and respecting life, depart from the earlier style of combining ethics with nurse/patient situations: it is as if the effort required to achieve such a rapprochment ran out of steam. The text remains interesting as a straight debate on medical ethics but nurses may feel an opportunity was lost. Professional matters reappear in the the final two chapters. There are some useful appendices.

This book would make a useful text for students of nursing ethics and for stimulating debate on ethical aspects of care. Nurse teachers could draw on it selectively for a range of preregistration courses.

PROFESSOR JACK HAYWARD, Nursing Research Unit, King's College, London.

\section{The nature of moral thinking}

Francis Snare, London and New York, Routledge, 1992, 187 pages, $£ 30.00$ hc, $£ 9.99 \mathrm{pb}$
The preface to this book says 'The Nature of Moral Thinking will satisfy the intellectually curious student, providing a solid and fair discussion of the classical philosophical questions about our moral thinking, surveying the main types of meta-ethical and normative ethical theories ...' Whether that is a fair assessment depends in part on what is meant by 'student'.

If it means someone studying moral philosophy in an institution of higher education, exposed to lectures, tutorials, classes, and other reading on the subject, then this book - which is based on the author's first-year lectures at Sydney University - could well prove a valuable handbook. Although it does not engage with live moral issues such as may arise in health care (the preface explains: 'Discussions of applied ethics are certain to be circumscribed unless underlying philosophical assumptions about deeper, more general issues are treated'), it touches on most of the topics with which moral philosophy has traditionally been concerned. I particularly enjoyed Snare's extended discussions of Plato's Euthyphro problem and of psychological egoism, and he is good at picking out varieties of relativism and subjectivism and shooting down sloppy-minded arguments that tend to get propagated in these areas.

On the debit side, it is a pity that, of the standard meta-ethical theories, he gives scant attention to intuitionism. Second, I think it was an error of judgement to include a chapter on the relativist theory of truth suggested in Plato's Theaetetus. It is based on lectures by David Armstrong, a colleague of Snare's, and stands as a selfcontained set-piece, impressive in itself but insufficiently connected to the book's official subject-matter of moral philosophy. Third, Snare makes little reference to the debates of the past decade about what has come to be called 'moral realism'. Perhaps these debates are too sophisticated for an introductory book; perhaps they merely offer new glosses on old positions; still, the omission seems a lack. Fourth, Snare is occasionally too terse and unforthcoming: there are remarks which read a bit like a lecturer's asides to a knowing audience (for example pages 48 and 173), and some ideas or theories (for example the prisoners' dilemma on page 170 , and non-natural properties on page 166) get mentions bereft of elucidation. Nevertheless, I shall be strongly recommending this book to my own first-year students.

The book cannot be so readily recommended to that other kind of student, the interested general reader uncushioned by an environment of institutionalised teaching of the subject. In particular, the occasional terseness may present difficulties for such a reader. What illumination would she or he get, for instance, from the following criticism (I quote it in its entirety) of the existentialist idea of an existential, self-creating choice of values: 'This is a bit mysterious' (page 157). Such undeveloped passages may, however, be a consequence of a sad fact: the author was still working on the manuscript when he died of cancer at the age of 47 , and revisions were completed and the book seen through the press by colleagues.

P F BROWNSEY Department of Philosophy, Glasgow University.

\section{Moral luck in medical ethics and practical politics}

\author{
Donna Dickenson, Aldershot, \\ Avebury, 1991,153 pages, $£ 30.00$
}

Problems of moral luck arise primarily from our tendencies, on the one hand, to hold agents responsible to a degree which depends at least partly on the outcomes of their decisions or actions (the killer drunken driver is more culpable than the non-killer), and, on the other, not to hold agents responsible for what is beyond their control.

The debate over moral luck in recent times was set in motion by a famous exchange between Bernard Williams and Thomas Nagel in 1976. In this book, Donna Dickenson takes that debate, which we might say has been carried on primarily at the level of theoretical ethics, and uses it to shed light on some practical issues in medical and political ethics. As she hopes, her practical discussions also help to elucidate certain theoretical matters.

The first three chapters outline the debate between Williams and Nagel, and investigate moral luck in Kantian and consequentialist ethics. Dickenson argues that Martha Nussbaum's critique of Kant in her book The Fragility of Goodness is unjustified: Kant does make room for moral risk 
and luck in the undetermined willing of the good will. Dickenson herself claims that a modified Nagelian Kantianism is the best approach to issues of moral luck in a chapter in which she finds problems of moral luck in consequentialism, whether it is based on actual or probable consequences.

A chapter is devoted to each of four practical issues.

The political questions discussed are those of secrecy and nuclear deterrence, and Dickenson argues against both. The first medical ethical issue covered is that of the allocation of scarce health care resources. Here Dickenson suggests that a lottery is required in allocation, except where the autonomy of nurses prevents their time being treated in the same way as other resources or where dependants are involved. Dickenson rejects the 'fair-innings' principle on the ground that there is no non-arbitrary view on what counts as a fair innings. A revamped argument from fairness, however, which centred purely on the relative lengths of life of candidates for treatment would not be vulnerable to this objection.

The second medical question discussed is that of informed consent. Here Dickenson runs the plausible line that a non-negligent doctor cannot be held responsible for a treatment's turning out badly if she had obtained informed consent from the patient beforehand.

A short review such as this cannot do justice to the richness and complexity of Dickenson's arguments. These issues - both theoretical and practical - are difficult, and she has perforce written a difficult book which will demand some knowledge of the literature in its readers.

ROGER CRISP St Anne's College, Oxford.

\section{Doctors, patients and the law}

\author{
Edited by Clare Dyer, Oxford, \\ Blackwell Scientific Publications, \\ 1992, 216 pages, $£ 15.99$
}

The last ten years have seen significant development in the burgeoning field of medical law. Such growth has been unrestrained by the traditional boundary of medical malpractice and has extended into laws regulating such activities as human fertility and patient access to records. This book is a timely summary of some of the more important issues arising in medical law.

Ms Dyer has assembled an impressive array of experts to contribute to Doctors, Patients and the Law. The book itself commemorates the centenary of the Medical Protection Society. The authors manage to outline the relevant issues in a way which is not only scholarly and lucid, but also interesting.

In the first chapter, Michael Jones examines the field of medical negligence and establishes the pattern for the rest of the book by using case law to focus on problems which may arise in everyday medical practice. Chapter two (written by Robert Lee) examines the areas of confidentiality and patient access to medical records. Chapters three and four examine consent to treatment by a capable patient (written by Ian Kennedy) and an incapable patient (written by Larry Gostin). In chapter five Sheila McClean examines the area of reproductive technology and includes in the discussion an interesting section on the effect that the various pieces of legislation have on maternal and fetal rights. Alexander McCall Smith tackles the difficult area of euthanasia in chapter six and J K Mason examines the law relating to organ transplants in chapter seven. Chapter eight (by Ian Dodds-Smith) examines rules regulating clinical research. Chapter nine (by Michael Spencer) looks at product liability. The last two chapters focus on the accountability of doctors (Roy Palmer) and employment rights (Brian Raymond).

The book is not simply a dry account of what the law is. The authors are quick to point out problems with existing law and to suggest new solutions. The book is remarkably up to date and references abound. It is a first-class source book.

The work has a couple of minor deficiencies. On occasion there are contradictions in the work (compare the differing definitions of competency offered on pages 58 and 76). The chapter on accountability and discipline, while being a good summary of the issues, suffers from a lack of footnotes referring to sections of the relevant acts. Finally, I believe the book would have benefited from an introductory chapter which explained in broad terms the contents and principal arguments of the authors. It would have been interesting to see a chapter on the NHS reforms and their effect on the delivery of medical prac- $m$ tice (though, admittedly, some of $\overrightarrow{\overline{\vec{S}}}$ these issues are explored tangentially $\tilde{\&}$ in other chapters). Similarly, a chapter on legal responses to the AIDS prob- $\overrightarrow{+}$ lem might have been interesting.

Overall, this book provides a fertile $\frac{\bar{\sigma}}{\sigma}$ source of information on the myriad $\overline{\bar{S}}$ legal regulations affecting medical $\overparen{D}$ practice.

\section{J A DEVEREUX $\vec{\circ}$} Keble College, Oxford.

\section{Ethics in nursing - third edition}

Martin Benjamin and Joy Curtis, New York, Oxford University Press, 1992, 248 pages, $£ 15.00 \mathrm{pb}$

This volume is a valuable further addition to the health care ethics literature. Were it not for the American setting and language it would be possible to recommend it wholeheartedly. As it stands, if readers afe equipped with a willingness to exe cise some mental agility in recognisin the many parallels within their ow country then they will be richly rewarded with some treasures in vivid case-studies and careful analysis.

The first two chapters introduce the reader to ethical analysis and ethical $\vec{F}$ frameworks. These are both lucid and 윽 accessible. The impression is of a well-grounded text for the novice and a useful though not wholly predictable review for the more experienced. Subsequent chapters centre upon $\overparen{D}$ ethical issues between nurses and $\frac{\sigma}{3}$ clients, nurse-physician relationships and dilemmas among nurses. In these of the reader's imagination is captured $₹$ with thoughtfully selected scenarios $ㅇ$ which are then subjected to rigorous analysis. The familiar issues of confi- $\frac{D}{0}$ dentiality, deception, autonomy and respect for persons are given due $\mathrm{N}$ weight. This interpersonal focus is replaced in the final two chapters by a concern with broader questions of $\omega$ firstly institutional and public policy and secondly macroallocation of 0 health care resources and justice. This last chapter constitutes the main new material for this third edition and considerably strengthens the volume by $\bar{O}$ immersing the discussion of health $\overrightarrow{\mathbb{D}}$ care ethics in collective concerns $\frac{\rho}{1}$

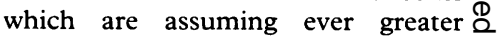
urgency in the latter part of the twentieth century. 